\title{
How do online reviewers' cultural traits and perceived experience influence hotel online ratings?
}

Article

Accepted Version

Mariani, M. and Predvoditeleva, M. (2019) How do online reviewers' cultural traits and perceived experience influence hotel online ratings? International Journal of Contemporary Hospitality Management, 31 (12). pp. 4543-4573. ISSN 09596119 doi: https://doi.org/10.1108/IJCHM-11-2018-0927 Available at https://centaur.reading.ac.uk/84917/

It is advisable to refer to the publisher's version if you intend to cite from the work. See Guidance on citing.

To link to this article DOI: http://dx.doi.org/10.1108/IJCHM-11-2018-0927

Publisher: Emerald

All outputs in CentAUR are protected by Intellectual Property Rights law, including copyright law. Copyright and IPR is retained by the creators or other copyright holders. Terms and conditions for use of this material are defined in the End User Agreement.

www.reading.ac.uk/centaur 
Central Archive at the University of Reading

Reading's research outputs online 


\title{
How do online reviewers' cultural traits and perceived experience influence hotel online ratings? An empirical analysis of the Muscovite hotel sector
}

\begin{abstract}
Purpose: This study examines the role and influence of online reviewers' cultural traits and perceived experience on online review ratings of Russian hotels by taking a direct measurement approach.

Design/methodology/approach: We adopt an Explanatory Sequential Research Design consisting of two stages. In the first stage, based on an a sample of almost 75,000 Booking.com online reviews covering hotels located in Moscow (Russia) we examine quantitatively to what extent the cultural traits of online reviewers and hotel guests' perceived experience in online reviewing affect online ratings using also censored regressions. In the second stage, we interpret the results in light of semi-structured interviews conducted with a convenience sample of managers.
\end{abstract}

Findings: Each of the Hofstede's cultural dimensions (namely individualism, masculinity, uncertainty avoidance and power distance) exerts a significantly negative influence on the hotel online ratings. More specifically, the higher the levels of individualism, masculinity, uncertainty avoidance and power distance, the lower hotel online ratings. Reviewers' perceived experience in online reviewing is negatively related to online ratings.

Research limitations/implications: The study's findings bear relevant practical implications for hotel managers and online platform managers in countries that are not typically covered by online consumer behavior studies in hospitality such as Russia. From a theoretical viewpoint, we contribute to cultural studies in hospitality management and marketing with a further development of the nascent research stream taking a direct measurement approach to the study of cultural influences on consumers' behaviors. Furthermore, we offer a better and in depth understanding of the role of cultural traits on eWOM, as well as international market segmentation theory in online settings.

Practical implications: The mixed method analyses conducted helps managers in the hospitality sector as well as platform managers and software developers to make sense of multiple individual reviewers' features including cultural traits, and perceived experience in online ratings.

Originality/value: The conjoint exploration of the effects of cultural differences and perceived experience in online reviewing adds to the nascent research stream taking a direct measurement approach to the study of the Hofstede's cultural dimensions on online consumers' behaviors. We make multiple theoretical and methodological contributions, highlighting that online hospitality customers cannot be considered as one homogeneous mass. Instead, the application of Hofstede's cultural dimensions allows identifying distinctively different online behaviors across international online customers: different online customer groups can be clustered into segments as they display different online behaviors and give different online 
evaluations.

Keywords: online reviews; online rating; hotels; cultural traits; online experience; censored regression; direct measurement approach; mixed-method study.

Article Classification: Research paper 


\section{Introduction}

Over the last six decades a number of different factors have accelerated the growth of the hospitality industry: economic factors (increase of GDP and available income for travels), demographic trends, globalization processes, consumption patterns, recognition of rights to travellers, development of technologies in both communication and transportation (UNWTO, 2017). More specifically, the advance of digital technologies and the growth of multi-sided digital platforms has led to a proliferation of online reviews (ORs) that represent a crucial source of information for both consumers and companies (Dellarocas et al., 2007; Hennig-Thurau et al., 2004; Kwok et al., 2017).

Consumers increasingly read online reviews to shape and inform their purchase decisions (Nielsen, 2015) as they are a paramount information source: the second after traditional word of mouth (WOM). The phenomenon is particularly relevant in the travel, hospitality and tourism domains, if we consider that the development of online travel agencies (OTAs) such as Booking and online travel websites such as TripAdvisor have made a large volume of information pertaining to travel, hospitality and tourism experiences available potentially to any online consumer (Cantallops and Salvi, 2014; Filieri, 2016; Mariani et al., 2018).

This trend is particularly relevant for hospitality services that are increasingly evaluated by means of online review platforms (Mauri and Minazzi, 2013; Kwok et al., 2017). A plethora of studies have been devoted to the analysis of guests' reviews of hotels (e.g., Sparks and Browning, 2011; Cheng et al., 2017, etc.) with a focus on both antecedents of online reviews and consequences for firms and customers (Cantallops and Salvi, 2014).

Hospitality services are mostly a matter of service encounters (Chen et al., 2012; Shostack, 1985) where service providers and service consumers often from different cultures interact with each other. Despite the relevance of cultural differences for service encounters in hospitality, to date cultural traits have been examined mostly through traditional survey methods bringing together a limited amount of service customers (e.g., Tse and Ho, 2009; Mattila, 1999, 2000). So far scholars have paid limited attention to the systematic effect that cultural factors (i.e., factors embedded in a national culture and that can affect customers' perceptions of a service: see Hwang and Seo, 2016) might have on the appraisal of hotel services in online settings, with a rare exception (Gao et al., 2018) that is a tangible signal of an emerging appetite to appreciate to what extent individual cultural traits might influence hotel consumers' online behaviours.

Indeed, while technology and globalization are certainly major game changers in today's hospitality sector and might apparently bring to a convergence in consumer behaviors (McLeod, 2004), consumers' (national) cultural traits and differences have still a paramount importance in the hospitality sector (Gao et al., 2018; Mattila, 1999; etc.) with a dearth of studies analysing the direct impact of cultural factors on consumers' behaviours in online settings. This study innovatively bridges this research gap and contributes 
to the nascent research stream in hospitality management studies taking a direct measurement approach (Huang and Crotts, 2019) to the study of cultural influences on hotel guests' behaviors. By adopting an explanatory sequential research design (Creswell, 2014), we conjointly examine the effects of online reviewers' cultural background and reviewers' perceived experience in online reviewing on online ratings to make sense comprehensively of how different features of the reviewer/reviews affect online review valence. Accordingly we contribute simultaneously to cultural studies in hospitality marketing and eWOM literature.

The study is structured as follows. The ensuing section illustrates the extant theory and relevant conceptual background and presents the five research hypotheses. Section 3 describes the research design and setting, as well as the methods deployed. The fourth section displays the research findings. Section 5 discusses the key findings drawing the major conclusions, and illustrating theoretical and practical implications, pointing out the major limitations and promising avenues for future research.

\section{Conceptual background and hypothesis development}

\subsection{Electronic word-of-mouth and hotel services}

Development in digital technologies has brought to the emergence of the Internet and later to the emergence and growth of multi-sided digital platforms (Parker and Van Alstyne, 2005). Several of these platforms, such as Tripadvisor, Booking but also AirBnB host an increasing number of online reviews. Online reviews are part of the electronic word-of-mouth (eWOM) whereby eWOM consists of positive or negative comments made by former, current, or potential customers about products, services, businesses that are shared with a high number of people and organizations through the Internet (Hennig-Thurau et al., 2004). Nowadays, online reviews represent a crucial source of information and knowledge for firms and customers in the travel and hospitality industries (Gretzel and Yoo, 2008; Litvin et al., 2008).

Cantallops and Salvi (2014) identify two research lines in the field of eWOM studies within hospitality management research: first, review-generating factors have been identified such as satisfaction/dissatisfaction, cognitive and psychological aspects, group influence, involvement, demographics (e.g., Kim et al., 2009; Nusair et al., 2011). Secondly, effects of eWOM have been analyzed from a consumer perspective including factors such as risk reduction, perceived credibility, helpfulness, decision making processes (e.g., Vermeulen and Seegers, 2009; Filieri and McLeay, 2014) and a company perspective encompassing factors such as reputation, performance, brand awareness and loyalty (e.g., Kim and Park, 2017; Nazarian et al., 2017).

Rarely eWOM scientific works have examined conjointly the influence of individual cultural traits and perceived reviewer experience on online consumer behavior. As far as cultural traits are concerned, $\mathrm{Au}$ et al. (2014) detect that Chinese hotel customers complain online less than non-Chinese customers on Ctrip 
and TripAdvisor. Luo et al. (2014) observe that review readers' level of individualism (measured based on the culture the readers belong to) acts as a moderating variable of the relationship between eWOM antecedents and perceived information credibility. Furthermore, they observe that the level of individualism negatively moderates the relationship between information credibility and information consistency/ rating. Ayeh et al. (2016) examine the intentions of US and Singapore travelers to use online hotel reviews and control by nationality. More recently, a study has deployed a specific cultural factor (i.e., power distance) to explain online hotel consumer behavior (Gao et al., 2018). Considering that to date scarce attention has been paid to the understanding of how cultural factors affect online consumer behavior and online consumers' evaluation of hotel services, in the next section we develop a review of pertinent cross-cultural studies.

\subsection{Cultural and cross-cultural studies in tourism and hospitality and the Hofstede's framework}

Culture has historically attracted the interest of scholars in a number of disciplinary fields, including sociology, anthropology, psychology, and management (Holden, 2004; Kroeber and Parsons, 1958; Luthans and Doh, 2009; Moran et al., 2007; Parsons, 1961; Rokeach, 1973; Schein, 1985). As it has been used in different disciplines, there are as many definitions of the notion of culture as the scholars that have tried to define it and within each discipline there are different theoretical perspectives and epistemological stances that we will not synthesize here for a matter of space and because it is beyond the purpose of this analysis.

Sociologists tend to define culture in terms of norms and rules. The American scholar Talcott Parsons considers culture as a subsystem of a more general system of action including "social systems ...()..., cultural systems, personality systems, and behavioral organisms; all four are abstractly defined relative to the concrete behavior of social interaction" (Parsons, 1971, p.4).

In anthropology, the current understanding of culture was greatly affected by several studies conducted between the Fifties and the Seventies. Perhaps the most dominant conceptual framework is the one introduced by the scholar Edward Hall that distinguishes between the concepts of high- vs. low-context culture (Hall, 1976). In his framework, different cultural contexts affect differently communication. More specifically, in high-context cultures messages are interpreted by leveraging 'unwritten rules' that are known and nonverbal communication dominates; on the other hand, in low-context cultures messages are interpreted by means of direct and explicit communication (through written and spoken words) as the context does not provide automatically self-evident rules. As such, this framework allows to illuminate how communication happens in different cultural contexts as well as different types of communication and skills (Hall, 1984).

Social psychologists have generally focused on values conceived as criteria and standards able to guide judgments, choices, attitudes, evaluations, arguments, and ultimately also actions. One of the most 
dominant frameworks adopted so far is the classification of cognitive values proposed and developed by the Polish-American scholar Milton Rokeach (1973) who distinguishes broadly terminal values from instrumental values. The former ones reflect the final goals of existence that individuals pursue to make their lives worthwhile (they could include respect and happiness). The latter ones encompass notions about desirable behaviors (including capability, responsibility, and honesty) that represent a means of achieving the aforementioned existential goals.

In the wide management field (including HR management, marketing, etc.), culture normally refers to organizational culture and national culture. While some studies have tried to examine the correlation between national and corporate/firm culture (e.g., Lee and Kramer, 2016), most studies have focused on either corporate/organizational (Cameron and Quinn, 1999; Schein, 1992) or national (Hofstede, 1980; Schwartz, 1992) culture.

One of the most cited frameworks of organizational culture was developed by Edgar Shein (1985, 1992). The model comprises three levels of organizational culture: artifacts, values, and assumptions. The three different levels mirror the extent to which different cultural phenomena are visible to the observer, with artifacts being the most tangible and concrete and assumptions being the least tangible and abstract.

Leveraging on values, Moran et al. (2007) shape a model including 10 different cultural dimensions of a group culture: sense of self and space, communication and languages, dress code and appearance, food and eating habits, time and time consciousness, relationships, values and norms, attitudes and believes, mental process and learning, and work habits and practices (Moran, et al., 2007).

Cameron and Quinn (1999) propose a framework comprising four competing values that relates to four types of organizational cultures: clan, adhocracy, market, and hierarchy. Every organization has its own mix of these four types of organizational cultures.

Values are also at the heart of the analysis of national cultures that have been examined in organizational contexts by the Dutch scholar Geert Hofstede starting from the Seventies. According to Hofstede (2001), culture is "the collective programming of the mind distinguishing the members of one group or category of people from others" (Hofstede, 2001, p. 9). As such, culture pertains to societal groups that can vary in size and in several cases they might be large enough to overlap with an entire nation or a country. The scholar posits that individuals from the same national culture share the same values (Hofstede, 1980) as values themselves can be regarded as the components of "mental programming" (Hofstede, 1980: p. 13). Originally, while studying work contexts of the multinational company IBM, Hofstede defined four dimensions of culture: power distance, individualism, masculinity, and uncertainty avoidance (Hofstede, 1980). Consistently with the early quantitative approach to measure culture adopted by Kluckhohn and Strodtbeck (1961), these dimensions are societal- and group-level dimensions and relate to vital issues that each society has to face to ensure its long-term survival. Power distance (PD) relates to the degree of 
acceptance of human inequality and disparity in a society or group. Individualism (IDV) relates to the way individuals integrate into primary social groups and the way they perceive their own welfare compared with societal welfare. Masculinity (MAS) relates to the way societal members value material achievement, competition and success. Last, uncertainty avoidance (UA) has to do with the degree of tolerance for uncertainty and risk. Later, two more dimensions were added: long-term orientation and indulgence (Hofstede et al., 2010). Hofstede and his colleagues have operationalized all of the aforesaid cultural dimensions through indices that cover a relevant number of countries, the only exceptions being long-term orientation and indulgence that are available for a smaller number of countries. Despite several criticisms of Hofstede's theoretical model (McSweeney, 2002), some authors (Holden, 2004; Beugelsdijk et al., 2018) underscore its importance as a useful methodological basis for research aimed at controlling for cultural values in management and business studies.

Certainly, and according to Graafland and Noorderhaven (2018) the "Hofstede's dimensions have become the de-facto standard in cross-cultural studies in management" (p. 959). An evidence of the previous statement is included in the analysis conducted by Engelen and Brettel (2011) that illustrates that the Hofstede's framework was used in more than $60 \%$ of the cross-cultural studies published in the leading management scientific journals over the period 1990-2008.

The Hofstede's framework has become increasingly relevant to interpret results in hospitality management and marketing research starting from the late Nineties. Thus, a study conducted by Mattila (1999) in two high-class hotels in Singapore empirically discovers that Western and Eastern (Asian) hospitality customers differ significantly in their appraisal of service quality and encounter. While business guests seem not to display major differences, Asian leisure guests evaluate service quality and encounters more conservatively than their Western counterparts. The author explains the differences based on Hofstede's power distance cultural dimension.

In their work on customers' complaint behaviours, Ngai et al. (2007) compare Asian and non-Asian hotel guests' attitudes towards hospitality services. The research reveals that Asian tourists avoid engaging in negative comments and complaints, unlike Western counterparts, consistently with Hofstede's framework (Hofstede, 1980; Hofstede et al., 2010). Although Ngai et al. (2007) cluster Asian countries into a homogeneous group, the research of Jahandideh et al. (2014) contravenes this position. The latter scholars clarify that Chinese and Arabic hotel guests demonstrate different complaint behaviors that address the basic principles of their culture. As Ngai et al. (2007) maintain, Chinese culture focuses on hierarchy and mastery, whereas Arabic cultural values focus more on group-relations in society and uncertainty avoidance.

Interestingly, most of the hospitality management and marketing studies deploying the Hofstede's framework, have deployed an indirect measurement approach to the study of (national) cultural influences on hotel guests' behaviours. As such, and in line with recent calls for the need to take a direct measurement 
approach to the study of national culture's influences on tourists' behaviour (Huang and Crotts, 2019), we contribute to the nascent research stream in hospitality marketing studies taking a direct measurement approach to the study of cultural influences on hotel guests' behaviours in online settings.

\subsection{Reviewer's experience}

Existing literature across a number of disciplines (including both social and hard sciences) has found that the accuracy of a specific reviewing and evaluation task increases as the experience of the reviewer/evaluator increases. Moreover, greater experience is typically associated with higher levels of expertise (Fogg, 2002) and competence (O'Keefe, 1998). For instance, as the experience of medical doctors increases, the more accurate and competent would be their diagnosis (e.g., Thompson et al., 2007). In the financial sector, the higher the level of experience of financial analysts with a specific firm, the higher the accuracy of the recommendation (e.g., Ramnath et al., 2008).

Online reviewer's characteristics such as reviewer experience and expertise have been the object of analysis in general marketing and hospitality marketing literature. However, the two terms experience and expertise have been used in a rather interchangeable way (see Xie and So, 2018). In this work we refer to reviewer experience as a broader term encompassing also expertise, and knowledgeability. It has been found that reviewer experience can affect how consumers perceive online reviews (Pentina et al., 2015; Zhang et al., 2014) and helpfulness (Huang et al., 2015) and that it moderates the relationship between review helpfulness and text attributes (Agnihotri and Bhattacharya, 2016).

\subsection{Hypotheses development}

In this section, we discuss consumer services research that has used the original version of the Hofstede's framework to construe findings in multi- and cross-cultural studies and develop our set of research hypotheses. Moreover, we leverage on received literature about the effect of experience in reviewing to examine the effect of experience on online review valence.

\section{Individualism (IDV)}

The cultural dimension of individualism-collectivism is perhaps the one that has received most of the scholarly attention so far within consumer services research (e.g., Mattila, 1999; Liu and McClure 2001; Reynolds and Smith, 2010; Sharma et al., 2012).

The literature related to the relationship between individualism/collectivism and consumer expectations has generated mixed results. Most of the studies seem to suggest that consumers espousing individualistic cultures have higher levels of expectations compared to customers espousing collectivistic cultures (Donthu and Yoo, 1998; Furrer et al., 2000; Laroche et al. 2004; Sharma et al., 2012; Liu et al., 
2001; Kim et al., 2014) and depend on outcomes rather than processes (Mattila, 1999). For example, Mattila (1999) has analysed how individualism, in addition to power distance and high- versus low-context communication (Hall, 1984), affects the hospitality service valuation process comparing three cultural groups: Caucasians, Asian Chinese and Asian Indian. She found that Western customers (typically characterized by high levels of individualism) care more about the physical environment than their Eastern equivalents.

On the other hand, there are studies that have taken a more nuanced approach to expectations. Reynolds and Smith (2010) argue that expectations are far from being a monolithic construct and that expectations of reliability and responsiveness tend to be high in developed and individualistic cultures whereas expectations of empathy and assurance are high in collectivistic cultures.

That said, we embrace what most of the literature seem to suggest: namely overall expectations are generally lower in collectivist than individualistic cultures (Donthu and Yoo, 1998; Reynolds and Smith, 2010; Sharma et al., 2012; Kim et al., 2014). Moreover, customers belonging to highly individualistic national groups (e.g., the UK, the US) display a tendency to complain more than their counterparts from collectivistic cultural groups (such as Singapore and China). In the same vein, Japanese guests prefer not to take any action in case of service failures in contrast with Americans (Huang et al., 1996). British guests were found to write complaint letters to the company's headquarters (Yuksel et al., 2006) more likely than Turkish, Dutch or Israeli guests. Based on the above discussion, we put forward our first research hypothesis:

H1: Reviewers' individualism (IDV) is negatively related to online review ratings; as such online hotel reviewers from cultural groups with higher individualism (IDV) tend to give lower online ratings.

\section{Masculinity (MAS)}

Consumer research related to services has devoted less attention to the cultural dimension of masculinity than to other dimensions such as individualism, with a few exceptions (Crotts and Erdmann, 2000; Furrer et al., 2000). For instance, Crotts and Erdmann (2000) find that masculine national cultures exhibit more interest in responsiveness and reliability and less tolerance in relation to service failures.

As far as service evaluations are concerned, consumers from high masculine societies have been found to have stronger motivations to give feedback than consumers in more feminine societies because they want to share with other their experience (Fang et al., 2013). These individuals are more likely to complain about poor service quality and they feel that they have the power to confront service providers for unsatisfactory experience or discontinue the experience (Torres et al., 2014). Furthermore, recent eWOM studies in cross-cultural settings reveal that customers belonging to societal groups with a feminine orientation (e.g., Chinese) tend to be more generous in their reviews (Fang et. al., 2013). Consequently, we 
put forward our second research hypothesis:

H2: Reviewers' masculinity (MAS) is negatively related to online review ratings; as such online hotel reviewers from cultural groups with higher masculinity (MAS) tend to give lower online ratings.

\section{Uncertainty avoidance (UA)}

Extant services marketing studies have emphasized that consumers characterized by lower levels of uncertainty avoidance display higher acceptance of risk and ambiguity than their equivalents in high uncertainty avoidance cultures (Donthu and Yoo, 1998; Ladhari et al., 2011; Sharma et al., 2012). More specifically, Donthu and Yoo (2008) discover that consumers belonging to high uncertainty avoidance cultures seek more proactively information about services and form higher expectations. Furthermore, as they are risk-averse, it is probable that they will share negative opinions and give lower ratings (Fang et. al, 2013). Ladhari et al. (2011) show that there are differences in service quality perceptions across low-high uncertainty avoidance levels, and find that consumers belonging to low uncertainty avoidance cultures give higher service evaluations than their counterparts. In other contexts, it has been found that higher levels of uncertainty avoidance are typically associated with lower evaluations (Voss et al., 2004; Reimann et al., 2008). Therefore, we put forward our third research hypothesis:

H3: Reviewers' uncertainty avoidance (UA) is negatively related to online review ratings; as such online hotel reviewers from cultural groups with higher uncertainty avoidance (UA) tend to give lower online ratings.

\section{Power distance $(P D)$}

As noted in previous studies, different service quality dimensions assume a varying importance based on the relative power of service customers/providers (Furrer et al., 2000). This implies that power distance assumes different meanings according to the specific industry contexts: in service activities such as medical and financial consulting, the service provider is more dominant based on her knowledge and experience; in hospitality and retail services, the provider is less dominant and displays a low status (Mattila, 1999). Hence, customers belonging to high PD cultures might expect the highest level of quality in service delivery (Ladhari et al., 2011; Mattila, 2000). This inference is supported by evidence highlighting that Western guests' evaluations of hotels are higher than Asian guests' ones (the latter ones displaying higher levels of power distance than the former ones).

The pioneering study looking at how power distance can affect customer evaluations in online settings has been conducted in the United States. Based on 243.000 TripAdvisor reviews for hotels in 24 US cities, Gao et al. (2018) find that reviewers' PD displays a negative association with online review ratings. In their study, Gao et al. (2018) focus on service providers that are characterized by high IDV and 
low PD. To validate their findings in a new context (Lynch et al., 2015), we study the relationship between PD and online ratings in a different setting (i.e., Russia) where service providers display low levels of IDV and high levels of PD. However, we maintain that the negative relationship will hold regardless of the country considered as what matter is the cultural traits of the online customers. Consequently, we hypothesize that:

H4: Reviewers' power distance (PD) is negatively related to online review ratings; as such online hotel reviewers from cultural groups with higher power distance (PD) tend to give lower online ratings.

\section{Reviewer's experience}

Experienced reviewers are not only perceived as helpful (Huang et al., 2015), but as their status as an expert will strengthen, they might express negative judgements as they self-conceptualize themselves as experts and opinion leaders (Kwok et al., 2017). This might lead the expert reviewer to enhance her self-esteem and be more critical (Lee et al., 2013). Therefore s/he could express more negative opinions as postulated in early research on negative reviewing (Amabile, 1983) as s/he will need to defend her status quo of competent reviewer in order to reach higher levels of visibility and popularity. Extant studies (Goes et al., 2014) have documented that as Internet users become more popular and renowned, they start writing more conservative reviews and this effect is higher the higher the volume of expert reviews (Zhang et al., 2016). Based on these findings, we hypothesize that:

H5: The higher the reviewers' perceived experience, the lower the online ratings they will give.

\section{Research setting, design and methodology}

\subsection{Empirical setting}

This study is situated in the Russian hotel industry for a number of reasons. First, Russia featuresamong the top ten destination countries regarding inbound international tourism flows (UNWTO, 2017) and it is therefore a major inbound market. Second, for historical reasons Russia has been developing its services sector according to a market-oriented approach only starting from the early 1990s after the breakdown of the Soviet Union. Third, the cultural background of service providers in Russia is different if compared to that of providers in other countries and for this reason the context under analysis represents an ideal one to validate and extend findings stemming from other contexts such as the United States, where the impact and influence of cultural differences on the online hotel ratings have been examined (see Gao et al., 2018).

The development of a market economy in Russia since the early 90s brought about the emergence of new markets and the transformation of existing ones and led to a change in the hotel business (Sheresheva et al., 2012). Currently the most developed hotel markets are Moscow, St. Petersburg and Sochi: they account for $70 \%$ of all international hotels in Russia (Ernst \& Young, 2018), (Figure 1). 


\section{[INSERT FIGURE 1 ABOUT HERE]}

The capital of Russia, Moscow, is the country's leader both in the number of existing hotels and those under construction. More than $25 \%$ of the total number of the foreign hotel chain operating in the Russian Federation are present in Moscow (Ernst \& Young, 2018). Almost all Russian hotel chains are also represented in Moscow. Moreover, Moscow ranks first in Russia in terms of tourist arrivals and is the most sought after destination (http://www.jll.ru/russia/en-gb/news/670/2017-on-moscow-and-stpetersburg-hotelmarkets).

\subsection{Research design, data and methods}

This study adopts a mixed-method research design, more specifically an Explanatory Sequential Design (Creswell, 2014; Creswell and Plano Clark, 2007). Explanatory Sequential Designs imply that "the researcher first conducts quantitative research, analyzes the results and then builds on the results to explain them in more detail with qualitative research. It is considered explanatory because the initial quantitative data results are explained further with the qualitative data. It is considered sequential because the initial quantitative phase is followed by the qualitative phase." (Creswell, 2014, pp. 15-16). This type of design is suitable when a more nuanced interpretation of quantitative findings is necessary, also in relation to the managers' and relevant stakeholders' viewpoints on the phenomenon under analysis.

We deployed triangulation as recommended within a mixed-method approach, which implies the use of heterogeneous data sources and methodologies to validate the quantitative findings and enrich their interpretation, and it is compatible also with triangulation in qualitative research designs (Denzin, 1978; Lincoln and Guba, 2000).

In the subsequent subparagraphs, we explicate the characteristics of the adopted methodology, describing in detail the first quantitative phase and the second qualitative phase.

\subsubsection{Quantitative phase}

\section{Data collection}

Data was collected from two different sources: Booking.com and the "Hofstede Center". The first source was deployed to gather online review data; the second to pull together data related to the cultural dimensions/variables.

Online hotel reviews were retrieved leveraging a big data approach (Mariani et al., 2018) from the

OTA Booking.com. The OTA was chosen due to its popularity worldwide (https://www.booking.com/content/about.en-gb.html), and also due its high share of certified online 
hospitality reviews globally (Mariani and Borghi, 2018).

Our study is situated in the Russian capital Moscow as it is a relevant business destination and certainly under-researched in eWOM studies. Its fast transition to a market service economy and the distinctive features of the service providers make it an interesting setting to tests the role played by consumers' cultural differences in the online evaluation of hospitality services. By leveraging a Python developed script, Muscovite hotels' online reviews were retrieved over a 25 months period starting in February 2015. Two relational datasets were built: the former encompassing company-level data and the latter one containing review-level data.

At the firm level, we retrieved information including the name of the hotel, its address, the hotel class, the overall rating. At the online review level, we scraped both metadata and data including the timestamp, stated name of the reviewer, her country of residence/origin, the number of reviews s/he wrote, the length of stay, the purpose of the trip (business or leisure), the experience in writing reviews of the reviewer, the travel companions (whether the travelers were travelling solo, in couple, in group, family, etc.). We gathered the aforesaid data over a 25 months window starting in February 2015. The data encompasses the overall population of hotel firms (657 hospitality firms displaying at least one review), that were reviewed in 387,812 reviews over the period under analysis. However, in line with Gao et al. (2018), to avoid home country biases, we only retained the reviews written by non-domestic authors (i.e., guests resident in countries other than Russia) and we eliminated the reviews with too many missing values. As a result, a total of 74,284 reviews were retained.

Last but not least, based on data from the Hofstede center we obtained the measures of the four focal cultural dimensions (PD, IDV, MAS, UA). Based on country names available in both datasets, we matched them to generate a final dataset. In our sample, the 74,284 reviews for the 602 hotels spanned the period February 2015- February 2017 and were written by reviewers from 93 different countries.

\section{Variables' operationalization}

This study's dependent variable is the Booking.com overall rating of the hotel ranging from 2.5 to 10.0 . We included a number of independent variables, such as the ensuing cultural indices: power distance (PD), individualism (IDV), masculinity (MAS), uncertainty avoidance (UA), i.e., the basic cultural dimensions identified originally by Hofstede (1980) and discussed in our literature review. The indices are available for all of the countries examined and vary in a range from 1 to 100 almost in a continuous way. Across the sample of 93 countries of origin that were considered in the sample, PD ranges from 13 to 100, IDV from 6 to 91 , MAS from 5 to 100 , and UA from 8 to 100 . The reliability and stability of these measures have been discussed widely in recent literature and we refer to Reisinger and Crotts (2010) and Huang and Crotts (2019) for more details. 
In addition, we included also control variables such as the length of stay (number of nights spent at the hotel) (LoS), the reviewer's experience in reviewing online (i.e., the volume of reviews written by a reviewer) (RE), the reviewer's knowledge of the destination (i.e., a badge indicating the extent to which the reviewer is an expert of the destination) (RK), the purpose of the trip (business or leisure), the type of travelling group (couple, family with children, solo etc.) and hotel category.

Table 1 below describes the variables of interest:

\section{[INSERT TABLE 1 ABOUT HERE]}

Table 2 summarizes the descriptive statistics:

\section{[INSERT TABLE 2 ABOUT HERE]}

Reviewers' experience (RE) is the only variable that does not display a normal distribution and as such it has been log-transformed. The variable correlation matrix also shows that all correlations are significant. The frequencies of the country of origin of the guests have been included in Appendix 1 .

\section{Data analysis}

Our five hypotheses were validated using both multivariate ordinary least squares (OLS) regression and Tobit regression. OLS and Tobit regressions were preferred over ordinal logistic regressions as the dependent variable (i.e., online ratings on Booking) varies from 2.5 to 10 in an almost continuous manner. The Tobit regression was used as a robustness techniques as the dependent variable is censored both on the left (there are no ratings below 2.5) and on the right (there are no ratings above 10.0) as clarified in previous research (Mellinas et al., 2015).

Therefore, the study's dependent variable, the overall rating of a review (Rating), was regressed (deploying both OLS and Tobit regressions for robustness check) against the main independent variables: individualism (IDV), masculinity (MAS), uncertainty avoidance (UA), power distance (PD), reviewer's experience (RE) in writing reviews. We controlled for reviewers' knowledge of the destination (RK), observed average rating (Obs_Avg_Rat), length of stay (LoS), hotel class, travel type (weather business or leisure), whether the hotel was part of a chain, as well as type of travelling group (solo, family, group, etc.).

\subsubsection{Qualitative phase}

After collecting and analyzing the quantitative data, we conducted 16 semi-structured interviews with managers and practitioners working in the Muscovite hospitality sector, to interpret in a more nuanced way the findings of the quantitative analysis and to gain a thorough picture of the way managers use and make sense of online ratings and use (or not use) nationality and cultural segmentation. Interviewees were chosen 
based on convenience grounds as one of the researchers has direct access to the Muscovite hospitality industry and the research team had previously collaborated with Muscovite hospitality managers in other research projects in the past. Respondents were chosen to cover evenly different types of hospitality firms (including different categories and geographical locations in Moscow). During this stage, at least two interviewers were present at each interview and, when possible, recorded the interviews (the hotel managers were mostly reluctant for us to do so). At the beginning of each interview meeting, we used two opening questions: "Do you analyze Booking.com reviews? If you analyze them, do you differentiate them based on the nationality of the reviewer?". Afterwards we asked: "Have you ever heard of the Hofstede's cultural dimensions?". If the answer was "yes", then we moved on to illustrating the papers' findings and asked the managers to comment on them; otherwise, we illustrated and explained to the managers in a very straightforward and simple way the meaning of cultural dimensions with the example of "power distance" and "individualism". Later we shared a hard copy of the paper and illustrated verbally the study's findings and asked them to give comments, based on their practical experience. Related questions were asked such as: "Are these results interesting or not for your marketing and management activities? Could they be used for your (digital) marketing strategy and/or to improve your segmentation of your customers?" The material was subsequently coded independently by each researcher (manually) and then compared.

\subsubsection{Data triangulation}

In line with the explanatory sequential research design adopted (Creswell, 2014), we deployed triangulation in terms of use of heterogeneous data sources and methodologies to validate the quantitative findings and enrich their interpretation. As such, we used triangulation at a higher level than how triangulation is deployed in purely qualitative research designs (Denzin, 1978; Lincoln and Guba, 2000). The analysis of both the qualitative and quantitative data acquired in this way has generated a series of findings that are presented and discussed in Section 4.

\section{Findings}

The outcomes of the quantitative analyses indicate that the coefficients for all the Hofstede's dimensions analyzed, namely individualism (IDV), masculinity (MAS), uncertainty avoidance (UA) and power distance (PD) are significantly negative in the OLS regression (respectively with $\mathrm{p}<0.05, \mathrm{p}<0.001, \mathrm{p}<0.10$, and $\mathrm{p}<0.001$ ) as clear from Table 3 and in the Tobit regression (respectively with $\mathrm{p}<0.01, \mathrm{p}<0.001, \mathrm{p}<0.10$, and $\mathrm{p}<0.001$ ) as clear from Table 4. These findings suggest that the reviewers' individualism, masculinity, uncertainty avoidance and power distance are negatively related to their online hotel ratings using both regression techniques. The aforementioned relationships should be interpreted at the societal group level so that the higher the degree of individualism, masculinity, uncertainty avoidance and power distance of a 
(national) societal group, the lower would be the online evaluation of hospitality services of the examined societal group.

\section{[INSERT TABLE 3 ABOUT HERE] [INSERT TABLE 4 ABOUT HERE]}

The groups of online reviewers from countries with higher individualism tend to contribute lower online evaluations. Accordingly, H1 is supported. Interestingly, the groups of reviewers from countries with higher masculinity are likely to provide lower online ratings. Therefore, $\mathrm{H} 2$ is supported. The groups of online consumers from countries with higher levels of UA tend to give lower online ratings. Thus, H3 is supported. The groups of consumers from higher power distance cultures give lower online ratings. Thus H4 is supported. Reviewer's experience in online reviewing influences negatively online ratings in both the OLS regression $(\mathrm{p}<0.05)$ and the Tobit regression $(\mathrm{p}<0.01)$. As such, H5 is supported. Interactions were also tested between the cultural traits and reviewers' experience but they did not yield significant results. We also carried out robustness checks by running a separate regression on subsample of reviews written by reviewers that were not originally from neighboring countries of Russia (such as Ukraine). The findings are consistent and robust and have been synthesized in Appendix 2.

In relation to the control variables, the reviewer's knowledge of a specific destination (i.e., the automated recognition by the platform that the reviewer has visited the focal destination more than one time) generates a negative and significant effect on reviewer's rating in both the OLS $(\mathrm{p}<0.05)$ and Tobit regressions ( $\mathrm{p}<0.05$ in the full model). Apparently, reviewers having a good knowledge of the destination where the hotel is located are more likely to have been hotel guests several times in the same destinations and have therefore developed a knowledge making them more demanding if their first experience was a positive one. Moreover, as the novelty effect about the destination vanishes, subsequent visits to the same destination could make the reviewers more demanding about the services offered by the hotel. Leisure travelers tend to give high ratings (positive coefficient and $\mathrm{p}<0.001$ using both OLS and Tobit regressions). Visitors travelling in company (e.g., with family) tend to give high ratings (coefficients are significantly positive); on the other hand, solo travelers seem to be neutral (the coefficient is positive but not significant) in both OLS and Tobit regressions.

Regarding the review-level control variables, the effect of the length of stay is positive but not significant while the coefficient of the observed average rating is significantly positive $(p<0.001)$ in both OLS and Tobit regressions. Finally, hotel related control variables have a positive impact on online ratings with the magnitude of the impact of hotel class increasing the higher the class of the hotel. 


\subsection{Enriching the interpretation of the quantitative findings through semi-structured interviews}

Most Muscovite hotels began implementing a digital marketing strategy 5-7 years ago and currently most of the digital marketing activities are aimed at increasing the share of bookings via the hotel website.

When asked about their own activities in relation to the Booking.com platform and more specifically about the use and analyses of Booking.com online reviews, Muscovite hotel managers told us that online reviews help them to identify the reasons of the customers' dissatisfaction with the hotel services but also gain insights on how to improve internal processes. However, most of the interviewees mentioned that they do not segment their online reviews based on the reviewer's country of origin. One respondent mentioned:

"Our hotel is business-oriented and international guest have been staying here since last 20 years. We organize cross-cultural training for our employees. However we do not segment online reviews based on nationality" (Interviewee \#9).

Another manager commented:

"We are happy to host foreign business and leisure guests. Based on their experience, our multilingual staff knows well the main behavior patterns and expectation of the European/Asian/South American/North American guests" (Interviewee \#11).

Only two managers said that they double check the nationality of the authors of on-line reviews. More specifically one of them stated:

"...we know that guests from some countries leave reviews much more frequently than others. Besides that, differences can be found also in the length and the details of the review: guests from China, for example, tend to write short notes while North Americans frequently leave a long detailed story". (Interviewee \#2)

Interestingly enough, even in those two hotels endowed with a Reputation/Quality manager, there are no structured activities as far as segmentation of reviews by country of origin is concerned. When looking at our quantitative findings, a few of the managers realized that the analysis could be very relevant to carry out targeted actions on the basis of the country of residence/origin and cultural traits of the reviewer.

One of them got interested in the Hofstede segmentation and mentioned that

“...I would expect a customer from an individualistic culture to give us lower ratings, and I see on average higher ratings from our Asian tourists than from Western Europeans. So what you mentioned is what we see in practice. However we do not segment by "individualism" which could be possibly a good idea. Indeed when we respond to a negative review we double check the nationality of the guest and also the language she used in her review: this can suggest how we should respond...but we do it empirically, there are no specific scripts" (Interviewee \#2)

The aforementioned quote is rather interesting as it suggests that the few hotel managers that use 
the country of origin as a heuristic to respond, value the Hofstede's dimensions, but still do not use them for segmentation purposes.

Other managers who read the paper mentioned:

"...I understand well that $€$-customers pay their money to get hotel services but also our reputed hotel can experience complaints... I observed that Asian guests are more forgiving and tolerant in these situations. This looks like what you mentioned as the feature of low masculinity as I understand." (Interviewee \#13)

"Uncertainty avoidance is about the clear or indecipherable look to the future? I would say that most of the foreign guests book their stay beforehand as they all need visa to get to the country. I cannot say there is some difference between the Western and Asian guests in terms of booking. So from this point of view I cannot distinguish them. As for the exact picture on what they want-the Westerns guests are more demanding. From the other side maybe Asian guests just do not share their feelings" (Interviewee \#1)

"...these dimensions of segmentation are interesting and I recall them from university. Perhaps they could be helpful for us but we would need to invest to train our employees to manually segment our guests by Hofstede's dimensions or perhaps invest some money in a software generating reports easy to understand for our employees. But indeed we do not even segment by country of origin." (Interviewee \#12)

Overall therefore it seems that: 1) only a few hotels are using strategically online reviews and carrying out online reviews segmentation (based on the country of origin for instance) to generate tailored interventions and responses; 2) those managers that are deploying online reviews strategically, are looking at nationalities rather than the Hofstede's dimensions while at the same time they recognize the value of a segmentation by cultural dimensions; 3) most of the managers (also in marketing/booking departments) do not carry out even any online review segmentation based on the reviewers' country of residence/origin. Among this group there are managers that are skeptical about both segmentation by country of origin and a segmentation by the Hofstede's dimensions.

All of the interviewees found that the effect of online review experience was in line with what they had guessed, based on their experience. For instance one said:

“... unfortunately we cannot see how many reviews a guest has already written at the moment of the booking via Booking. If we could, I think we would treat her/him better than our average guests and to the highest possible standards. Indeed many of those reviewers can be very nasty in their feedback." (Interviewee \#8) 


\section{Discussion and Conclusions}

\subsection{Conclusions and key findings}

Based on a large amount of hotel reviews related to hospitality services in the most visited destination city in the Russian Federation, this study has tried to gauge if and to what extent the espoused societal cultural values and individual online experience of online consumers influence their online rating behaviors. By leveraging a direct measurement approach to national culture, we therefore examined the effect on online ratings of the four cultural dimensions identified by Hofstede (1980) conjointly with reviewers' experience in writing reviews, by adopting both OLS and Tobit regressions.

Seven key findings emerge from the analysis. First, online hotel reviewers belonging to individualistic societal groups are likely to give low online ratings. This finding is coherent with extant studies emphasizing that consumers belonging to individualistic societies tend to have higher levels of expectations compared to consumers belonging to collectivistic societies (Donthu and Yoo, 1998; Furrer et al., 2000; Laroche et al., 2004; Reynolds and Smith, 2010; Sharma et al., 2012) and rely more on outcomes than processes (Mattila, 1999). Second, online hotel reviewers belonging to masculine societal groups appear to give low online ratings. This result is compatible with traditional survey-based literature emphasizing that customers from masculine societies are keen on reliability and responsiveness and less tolerant of service failures (Crotts and Erdmann, 2000). It also partially reinforces the finding that women are lavish in online ratings (Gao et al., 2018). Third, online hotel reviewers from societal groups characterized by high levels of uncertainty avoidance give low online ratings: the result is compatible with previous studies emphasizing that customers belonging to high UA societal groups have a less favorable perception of services quality than their counterparts belonging to low UA societal groups due to lower tolerance for ambiguity than their counterparts (Ladhari et al., 2011) and cannot cope effectively with uncertainty in the short term (Donthu and Yoo, 1998; Ladhari et al., 2011; Sharma et al., 2012). Fourth we corroborate previous findings in the literature suggesting that reviewers from societal groups with high power distance give low evaluations both in offline settings (Ladhari et al., 2011; Mattila 2000) and in online ones (Gao et al., 2018). However, we add to extant findings in online settings, as our hypothesis is tested in a country, Russia, where service providers are characterized by low levels of IDV and high PD that certainly differ from the high levels of IDV and low PD that characterize countries such as the United States (Gao et al., 2018). Fifth, the reviewers' experience in online reviewing affects negatively and significantly the online ratings. A plausible interpretation might be that experience in reviewing is a good proxy of experience in travelling that has been found to impact negatively online ratings (Gao et al., 2018). Sixth, we speculate that as the reviewer's knowledge of the destination increases, her online ratings will decrease as the novelty effect associated with the discovery of a new attractive destination (Assaker et al., 2011) will be progressively compensated by a more objective assessment of the hotels serving that destination. Seventh, 
this is the first study that, by recognizing that the dependent variable (i.e., online ratings on Booking) is continuous but by construction censored both on the left and on the right (see Mellinas et al., 2015), has adopted also a Tobit regression technique in addition to an OLS technique to ensure accuracy and robustness of the findings.

In general, our findings offer a comprehensive understanding of how and to what extent cultural differences across nations and societal groups - measured along the four cultural dimensions included in the original version of the Hofstede's framework (1980) - can influence the online ratings and behavior of online customers. Moreover, the findings are consistent regardless of the regression technique adopted (i.e., OLS or Tobit) and are rather robust as we analyze more than 74,000 customers from 93 different countries. The study's findings show that consumers' espoused culture makes a difference in their online behavior. As described in cross-cultural consumer studies (De Mooij and Hofstede, 2011), consumers' cultural background influence their attitudes and perceptions. Our study finds that cultural differences (all of them) affect significantly service evaluations in online settings.

\subsection{Theoretical implications}

This study offers several theoretical insights that are relevant for the hospitality management and marketing literature. First, as Hofstede's dimensions are group-level dimensions that differentiate two or more societal groups or nations/countries, our analysis adds to cultural studies in hospitality management and marketing, revealing that online customers from distinctively different societal groups, by sharing intentionally or unintentionally, as well as consciously or unconsciously, the same cultural values, react similarly to similar hospitality service provisions, other things being equal. This is in line with the received empirical findings that culture subconsciously or consciously affects perceptions and therefore also how consumers filter incoming information (Cleveland et al., 2016) and eventually express their evaluations. Our empirical evidence, suggests that cultural values represent asymptotic tendencies of collective values and norms at the societal group level (whereby the societal group could involve one or even more national groups displaying strong cultural similarities in terms of values) that - by psychologically imprinting individuals - affect guests' online evaluations and judgments. As such, online behaviors (e.g., online human evaluations and judgments) are partially culturally-bounded and culturally-dependent, explaining why hotel guests with distinctively different cultural backgrounds evaluate online a similar hospitality service differently

Second and linked to the previous point, our findings strengthen international market segmentation theory in general (Allenby et al., 2002; Cleveland et al., 2011, 2016; Dibb and Simkin, 2001) and hospitality and tourism market segmentation in particular (Bowen, 1998; Dolnicar, 2004; Du et al., 2016) and enrich the debate revolving around the divide between research and practice in segmentation (Dolnicar and Lazarevski, 2009). Theoretically, our study's results provide evidence that online hospitality customers 
cannot be considered as one homogeneous mass. Instead, the application of the Hofstede's cultural dimensions allows identifying distinctively different segments of online customer groups based on their shared cultural values. Each segment is relatively homogenous internally in terms of consumers' cultural traits and heterogeneous compared to different segments. In other words, it is possible to include into a segment different customer groups that display (intentionally or unintentionally, consciously or unconsciously) similar cultural values as captured by the Hofstede's cultural dimensions of power distance, individualism, masculinity and uncertainty avoidance.

Third, this work reveals that most (if not all) of the effects of customers' cultural traits on the evaluation of hospitality services are extremely similar regardless of the specific setting (online vs. offline) where the evaluation takes place. This generates important theoretical implications as it suggests that the effect of the customer's cultural traits on services evaluations is equally important in offline and in computer-mediated environments. The direct effects described here are compatible with the moderation effects of cultural orientation regarding the acceptance of online hotel reviews in online setting (Ayeh et al., 2016). As such this finding seems to strengthen the idea that there is an interplay between psychology and culture as they co-evolve influencing each other (Lehman et al., 2004) and this holds both in offline and online settings.

Fourth, we contribute to the nascent research stream in hospitality management studies taking a direct measurement approach to the study of national culture's influences on hotel guests' behaviors. Accordingly, we build a more joined-up body of research with a recent study by Huang and Crotts (2019) that examines the relationship between the Hofstede's dimensions and tourists' satisfaction with destinations. Rather than focusing on destinations, we focus on hospitality services and thus, to our knowledge, this is one of the first attempts to adopt a direct measurement approach to the study of national culture's influences on hotel guests' online behaviors by looking at all of the four original Hofstede's dimensions (conjointly with reviewers' experience). Adopting a direct measurement approach is of the essence as it allows to capture online behaviors thus reducing the risk of answer biases that are frequent in traditional survey research (Dolnicar et al., 2016).

Fifth, despite several studies relying on indirect measurement (e.g., Pizam and Sussmann, 1995; Reisinger and Turner, 1997) have focused on the influence of one or two of the Hofstede's dimensions on customers' service evaluations measured in offline contexts and on small samples of customers (displaying limitations in research designs and data that negatively influence the generalizability of their findings), this work contributes novel knowledge to the eWOM literature as we examine online rating behaviours from the perspective of the Hofstede's cultural dimensions that have been rarely examined in the online review domain, except for a few cases (e.g., Gao et al., 2018). Accordingly we improve the generalizability: a) of the effects of the four Hofstede's dimensions on services customers' evaluations and b) of the way cultural values can influence hospitality service evaluations (Torres et al., 2014; Sabiote-Ortiz et al., 2016) in online 
settings.

Sixth, virtually we contribute also to social identity theory (Tajfel and Turner, 1986) perspectives on marketing (Zeugner-Roth et al., 2015) as we show that belonging to a specific cultural group with a specific socio-cultural identity such as a national identity affects online behaviors of the societal groups, thus extending and strengthening international marketing theory developed in offline settings (Cleveland et al., 2016; Nakata and Sivakumar, 2001). While we do not rely on national or ethnic identity scales (e.g., Phinney and Ong, 2007; Cleveland et al., 2016), we can deduce that social groups in the examined computermediated settings identify themselves, overtly or implicitly, intentionally or unintentionally, with specific cultural traits that, in line with social psychology work (Baumeister and Leary, 1995) represent the ground to understand how the norms and perspectives of a focal societal group influence individual attitudes and behaviors of in-group members despite globalization (de Mooji and Hofsede, 2011), thus discounting the apparent emergence of a convergence of consumer behaviors across nations (Alden et al., 2006; McLeod, 2004). This seems consistent with recent findings that "yet, national identity is, paradoxically, perhaps becoming more important" (Cleveland et al., 2016, p. 1099) for customer groups whereby individuals belonging to different socio-cultural groups develop a social identity that affects their behaviors.

\subsection{Practical implications}

A number of practical implications stem from this study, including implications for the Russian hospitality industry, practitioners and hotel managers, and software developers and managers of online review platforms.

In relation to the entire industry, the findings of the quantitative analysis, matched with interviews with industry players, reveal a challenge that hotels are currently facing. Indeed competition in the Moscow hotel sector is mounting and there is almost an absence of reliable benchmarking practices to monitor and analyze customers' online reviews comparatively and vis-à-vis the local competitive set.

However, the interviews carried out for this study and additional interviews carried out in the framework of a wider ongoing research project highlight that there seems to be a reduced number of digital marketing strategists (such as reputation managers) dealing specifically with online reviews. Accordingly, with the caveat that more time would be needed to gain a thorough and in depth understanding of internal organizational processes, we believe that hotels could develop clearly focused strategies to deal with online reviews in general. Moreover, we suggest that strengthening the communication between marketing/booking departments and front-office departments could be functional for the implementation of the strategies of the marketing department in relation to online reviews. In general, a more functional connection may be shaped by fostering inter-departmental (and intra functional) relationships between the marketing/booking department and the front office to bridge potential gaps between strategies and tactics 
as far as online reviews are concerned.

We found that hotel managers in Moscow do not segment their online reviewers by their country of origin even if they look at the nationality of the reviewer when they read online reviews. Moreover, while Hofstede's dimensions are relatively well-known among industry practitioners that are mostly well educated on average in Russia (Predvoditeleva at al., 2019), their application to the analysis of online reviews was never mentioned during the interviews and apparently it is not included in Russian reference hotel practitioners' forums and business conferences revolving around digital marketing in hotels. However, our research suggests that cultural dimensions affect online review ratings. Thus, stakeholders active within the Muscovite hotel industry - as hotel managers, consultants, strategists, professional associations, etc. - are encouraged to explore cultural differences as crucial drivers for the effectiveness of online marketing practices in business conferences, workshops, and professional networks both online and offline.

As far as hotel managers are concerned, they should not only pay attention to review ratings themselves but also gain insights based on the reviewer's nationality. One of the preconditions to get high hotel ratings for hotel managers is to shape an effective management system, improving intra-organizational communications and decision making.

Interestingly, it seems that there is consensus among a number of interviewees that the insights derived from Booking online reviews could be potentially used in social media marketing and promotion activities. For instance, if hotel managers know what a specific national segment (say Spaniards) liked about the hotel in their online reviews, they could use this information to create content that they could post on their social media and then run targeted social media advertising campaigns using exactly that type of content. This way the specific national segment would be targeted with a tailored online promotion. We believe that Muscovite hotels should focus more on the national and generally cultural features of their Booking.com reviewers and use this information as a knowledge base to shape the hotel's promotional strategies.

Additional implications relate to how hotel managers can use a nationality-based and Hofstedebased segmentation to: (1) Improve their understanding of consumers with a correct interpretation of the relationship between reviewer's nationality and rating; (2) boost online ratings; (3) improve managerial practices when the ratings are low.

To improve their understanding of consumers, managers should triangulate the information regarding the nationality of the reviewers with their knowledge of behaviors across nationalities. For example, individuals from countries with high individualism are arguably more emotionally independent (Hofstede, 1980) and we conjecture therefore that the variance in their ratings could be higher than the variance for guests from high collectivist countries who prefer to keep group consensus (Laroche et. al., 2006). Therefore we might imagine that guests from the latter group, when providing online reviews, might 
tend to follow their reference group when evaluating a particular hotel (i.e. they tend to replicate previous ratings provided by guests from the same nationality/cultural group), as do individuals from collectivist societies who normally trust their in-group members. Our recommendation is therefore that managerial attention should be addressed to reviews from guests from countries with an individualistic culture as they tend to express their opinions more freely and this might be a source of high variation in their online ratings which is not necessarily always associated to helpfulness (Racherla and Friske, 2012).

An additional example of the need to appropriately use information on cultural differences in interpreting the ratings is that guests from feminine countries are less likely to give negative reviews because of their fear of "losing their face" (Ngai et al., 2007). Therefore, very few negative reviews given by such guests might not actually mean that all guests from feminine countries are happy; they may in fact be unsatisfied but simply do not want leave a negative review. Hence, we recommend that managers should triangulate also sources of information other than Booking.com reviews to obtain more accurate insights on their customers and improve services accordingly.

Nationality segmentation can be leveraged by hotel managers also to enhance online ratings. For example, individuals from high power distance countries "pay more attention to status-related activities with the motivation to pursue power" (Wen et al., 2018, p. 9). We believe that this will be reflected in their online behavior; thus, they will be more likely to state in a review if they received a bonus or privilege of some sort (e.g., room upgrade etc.), as this increases their status. As decisions regarding guests' upgrades or other bonuses/benefits pertain to the front office, it is recommended that hotels empower (Bowen and Lawler, 1992) front-line personnel to use differently their degrees of managerial freedom based on the nationality of the customer

Last, information about the reviewer's nationality can also be used to leverage on low ratings to the hotel's benefit through management responses that can "affect hotel performance through the increased ratings and volume of customer eWOM" (Xie et. al., 2016, p. 2028). While it is clear that managerial responses can increase hotel ratings, it is not realistic to respond to all reviews, owing to the limited employees available in times of economic crisis. However, we do believe that managers should also reply to some positive reviews, even if the management company/brand internal scripts do not make this mandatory. Managers can use the tactics proposed by Xie et al. (2016), selectively responding to individual positive reviewers (for instance those with the higher levels of experience in writing Booking reviews) who can serve as opinion leaders. In the case of responses from reviewers of different nationality this tactic could be particularly effective when replying to individuals from feminine societies who value reciprocity and benevolence and might therefore be more likely to like the reply.

An additional idea of using online review nationality segmentation to increase ratings on Booking.com in service failures situations concerns individuals from societies with high masculinity that 
are concerned with problem-solving. It could be useful to serve this group of customers in a targeted manner when service failures occur, and use the service recovery paradox (McCollough et al., 2000) because quick and effective service recovery increases the customer's satisfaction (De Pelsmacker et al., 2018) and naturally leads to higher ratings from hotel guests. We conjecture that this might work better for the nationality segments displaying higher values of masculinity.

Besides accommodation, hotels can offer a wide range of other services including restaurant services. Most Muscovite hotel restaurants are busy mostly for breakfast while the occupancy rate declines at lunch and dinner time. We believe that in order to increase the online hotel rating hotels should customize restaurant services to the demands of guests of different national cultures and restaurant clients not staying at the hotel. As those from high individualistic and high collectivistic cultures (Li et al., 2011) demonstrate different habits in food consumption, the customization can affect the size of the tables, their arrangement and organization of the breakfast/dinner zone itself.

As far as software developers of online review platforms are concerned, they might shape more comprehensive algorithms to improve the usefulness of online reviews (Liu and Park, 2015) by matching countries of origin and residence, and clusters based on cultural factors/dimension. Accordingly, readers of reviews might find particularly helpful to read online reviews from guests sharing similar cultural characteristics. Furthermore, as Muscovite hotels use different software to analyze online reviews (including TrustYou, Revinate and Medallia Experience Cloud), there might be implications also for these latter companies. Indeed the three aforementioned software companies offer several ways to analyze online reviews, but none of them allows to filter reviews based on the reviewer's country of origin as it happens on Booking.com. We would therefore suggest those software companies to develop mechanisms to allow fast reporting of aggregate statistics about the reviewer's country of origin and related Hofstede's cultural dimensions.

\subsection{Limitations and Future Research}

This study is not without limitations. First, the model specification might be enriched by adding reviewerlevel variables (such as age) as mediators to understand to what extent they can moderate the impact of the Hofstede's cultural dimensions on online ratings. Second, while this is one of the very few studies conducted on an online review platform other than TripAdvisor, it would be worthwhile to conduct a similar study on both other independent online review platforms and OTAs (e.g., Expedia) to engender additional insights on online consumer behavior. Last, to ensure generalization it is of paramount importance to validate the study's findings by means of multi-country-multi-destination comparisons.

Future research might employ the CVSCALE developed originally by Yoo et al. (2011) and later tested by Mazanec et al. (2015) to derive more fine grained conclusions of the effects of individual-level 
cultural traits on online customers' hospitality service evaluations. Indeed this might "allow extension of Hofstede's pioneering work in ways previously not possible" (Mazanec et al., 2015, p. 303). Second and relatedly, the presence of subcultures within each national group should be further investigated, thus extending previous findings about the increasing relevance of within-nation variability of cultural traits (Reisinger and Crotts, 2010). Last, comparing different services sectors including also financial, medical and consultancy services might help strengthening the cross-industry generalizability of the findings. 


\section{References}

Agnihotri, A. and Bhattacharya, S. (2016), “Online Review Helpfulness: Role of Qualitative Factors", Psychology \& Marketing, Vol. 33 No. 11, pp. 1006-1017.

Alden, D. L., Steenkamp, J. -B. E. M. and Batra, R. (2006), “Consumer attitudes toward marketplace globalization: Structure, antecedents, and consequences", International Journal of Research in Marketing, Vol. 23 No. 3, pp. 227-239.

Allenby, G., Fennell, G., Bemmaor, A., et al. (2002), "Market Segmentation Research: Beyond Within and Across Group Differences”, Marketing Letters, Vol. 13 No. 3, pp. 233-243.

Amabile, T. (1981), "Brilliant but cruel: perceptions of negative evaluators”, Journal of Experimental Social Psychology, Vol. 19, pp. 146-156.

Assaker, G.,Vinzi, V.E. and O'Connor, P. (2011), "Examining the effect of novelty seeking, satisfaction, and destination image on tourists' return pattern: A two factor, non-linear latent growth model”, Tourism Management, Vol. 32, No. 4, pp. 890-901.

Au, N., Buhalis, D. and Law, R. (2014), "Online complaining behavior for Mainland China hotels: the perception of Chinese and Non-Chinese customers", International Journal of Hospitality and Tourism Administration, Vol. 15 No. 3, pp. 248-274.

Ayeh, J.A., Au, N. and Law, R. (2016), “Investigating cross-national heterogeneity in the adoption of online hotel reviews", International Journal of Hospitality Management, Vol. 55, pp. 142-153.

Beugelsdijk, S., Kostova, T., van Essen, M., Kunst, V. and Spadafora, E. (2018), "Cultural distance and firm internationalization: A meta-analytical review and theoretical implications", Journal of Management, Vol. 44 No. 1, pp. 89-130.

Baumeister, R. F. and Leary, M. R. (1995),'The need to belong: Desire for interpersonal attachments as a fundamental human motivation”, Psychological Bulletin, Vol. 117 No. 3, pp. 497-529.

Bowen, J.T. (1998), "Market segmentation in hospitality research: no longer a sequential process", International Journal of Contemporary Hospitality Management, Vol. 10 No.7, pp. 289296.

Bowen, D. E. and Lawler, E. E. (1992), “The Empowerment of Service Workers: What, Why, How, and When", Sloan Management Review, Vol. 33 No. 3, pp. 31-39.

Cameron, K. S. and Quinn, R. E. (1999). Diagnosing and changing organizational culture: Based on the competing values framework. Reading, MA: Addison-Wesley.

Cantallops, A.S. and Salvi, F. (2014), "New consumer behavior: A review of research on eWOM and hotels", International Journal of Hospitality Management, Vol. 36, pp. 41- 51. 
Chen, R.X.Y., Cheung, C. and Law, R. (2012), “A review of the literature on culture in hotel management research: What is the future?", International Journal of Hospitality Management, Vol. 31, pp. 5265 .

Cheng Chu Chan, I., Lam, L.W., Chow, C. W.C. Hoc Nang Fon, L. and Law, B. (2017), "The effect of online reviews on hotel booking intention: The role of reader-reviewer similarity", International Journal of Hospitality Management, Vol. 66, pp. 54-65.

Cleveland, M., Laroche, M., Takahashi, I. and Erdoğan, S. (2011), "Cross-linguistic validation of a unidimensional scale for cosmopolitanism”, Journal of Business Research, Vol. 67 No. 3, pp. 268277.

Cleveland, M., Rojas-Méndez J.I., Laroche, M. and Papadopoulos, N. (2016), “Identity, culture, dispositions and behavior: A cross-national examination of globalization and culture change", Journal of Business Research, Vol. 69, pp. 1090-1102.

Creswell, J. W. (2014). Research Design: Qualitative, Quantitative and Mixed Method Approaches. Fourth Edition, Sage Publications, Thousand Oaks, CA.

Creswell, J. W. and Plano Clark, V. L. (2007), Mixed methods research, Sage, London

Crotts, J.C. and Erdmann, R. (2000), “Does national culture influence consumers' evaluation of travel services? A test of Hofstede's model of cross-cultural differences", Managing Service Quality: An International Journal, Vol. 10 No. 6, pp. 410-419.

de Mooij, M. and Beniflah, J. (2016), "Measuring cross-cultural differences of ethnic groups within nations: Convergence or divergence of cultural values? The case of the United States", Journal of International Consumer Marketing, Vol. 29 No. 1, pp. 2-10.

de Mooij, M. and Hofstede, G. (2011), "Cross-Cultural Consumer Behavior: A Review of Research Findings", Journal of International Consumer Marketing, Vol. 23, pp. 181-192.

De Pelsmacker, P., Tilburg, S. and Holthof, C. (2018), "Digital marketing strategies, online reviews and hotel performance", International Journal of Hospitality Management, Vol. 72, pp. 47-55.

Dellarocas, C., Zhang, X. and Awad, N. F. (2007), "Exploring the value of online product reviews in forecasting sales: The case of motion pictures", Journal of Interactive Marketing, Vol. 21, pp. 2345 .

Denzin, N. (1978). Sociological Methods: A Sourcebook. NY, McGraw Hill.

Dibb, S. and Simkin, L. (2001), "Market Segmentation: Diagnosing and Treating the Barriers", Industrial Marketing Management, Vol. 30 No. 8, pp. 609-625.

Dolnicar, S. (2004), "Beyond "commonsense segmentation": A systematics of segmentation approaches in tourism”, Journal of Travel Research, Vol. 42 No. 3, pp. 244-250.

Dolnicar, S. and Lazarevski, K. (2009), "Methodological reasons for the theory/practice divide in market 
segmentation", Journal of Marketing Management, Vol. 25, pp. 357-373.

Dolnicar, S., Grün, B. and Leisch, F. (2016), "Increasing sample size compensates for data problems in segmentation studies”, Journal of Business Research, Vol. 69 No. 2, pp. 992-999.

Donthu, N. and Yoo, B. (1998), “Cultural Influences on Service Quality Expectations”, Journal of Service Research, Vol. 11 No. 2, pp. 178-186.

Du, F., Yang, F., Liang, L and Yang, Y. (2016) "Do service providers adopting market segmentation need cooperation with third parties?: An application to hotels", International Journal of Contemporary Hospitality Management, Vol. 28 No. 1, pp.136-155,

Engelen, A. and Brettel, M. (2011), “A Cross-Cultural Perspective of Marketing Departments' Influence Tactics”, Journal of International Marketing, Vol. 19, No. 2, pp. 73-94.

Ernst \& Young (2018), “International Hotel Brands in Russia 2018”, available at: http://www.ey.com/Publication/vwLUAssets/EY-international-hotel-brands-in-russia2018/\$File/EY-international-hotel-brands-in-russia-2018.pdf (accessed October 29 2018).

Fang, H., Zhang, J., Bao, Y. and Zhu, Q. (2013), “Towards effective online review systems in the Chinese context: A cross-cultural empirical study", Electronic Commerce Research and Applications, Vol. 12 No. 3, pp. 208-220.

Filieri, R. (2016), “What makes an online consumer review trustworthy?", Annals of Tourism Research, Vol 58, pp. 46-64.

Filieri, R. and McLeay, F. (2014), "E-Wom and accommodation. An Analysis of the factors that influence travelers' adoption of information from online reviews", Journal of Travel Research, Vol. 53 No. 1 , pp. $44-57$.

Fogg, B.J. (2002), "Prominence-Interpretation Theory: Explaining How People Assess Credibility". A Research Report from the Stanford Persuasive Technology Lab, Stanford University. Retrieved from http://credibility.stanford.edu/pit.html.

Furrer, O., Liu, B.S.-C. and Sudharshan, D. (2000), "The Relationships between culture and service quality perceptions: basis for cross-cultural market segmentation and resource allocation", Journal of Service Research, Vol. 2 No. 4, pp. 355-371.

Gao, B., Li, H., Liu, S. and Fang, D. (2018), "How power distance affects online hotel ratings: The positive moderating roles of hotel chain and reviewers' travel experience", Tourism Management, Vol. 65, p. 177.

Goes, P. B., Lin, M. and Yeung, C. A. (2014), "Popularity effect" in user-generated content: evidence from online product reviews", Information Systems Research, Vol. 25 No. 2, pp. 222-238.

Graafland, J. and Noorderhaven, N. (2018). "National culture and environmental responsibility research revisited", International Business Review, Vol. 27 No. 5, pp. 958-968. 
Gretzel, U. and Yoo, K. (2008), “Use and impact of online travel reviews.” In P. O'Connor, W. Hopken, and U. Gretzel (Eds.), Information and communication Technologies in tourism, Vol. 2, pp. 35-46. Wien/New York: Springer-Verlag.

Hall, E.T. (1976), Beyond Culture, Garden City, NJ: Doubleday.

Hall, E.T. (1984), The Dance of Life, Garden City, NY: Doubleday.

Hennig-Thurau, T., Gwinner, K.P., Walsh, W. and Gremler, D.D. (2004), "Electronic word-of-mouth via Consumer-opinion platforms: What motivates consumers to articulate themselves on the Internet?", Journal of Interactive Marketing, Vol. 18 No. 1, pp. 38-52.

Hofstede, G. (1980), Culture's consequences: international differences in work-related values, Beverly Hills, CA: Sage Publications.

Hofstede, G. (2001), Culture's consequences: comparing values, behaviors, institutions, and organizations across nations (2nd ed.), Thousand Oaks, CA: Sage Publications.

Hofstede, G., Hofstede, G.J. and Minkov, M. (2010), Cultures and Organizations: Software of the Mind (3rd ed.), McGraw-Hill, USA.

Holden, N. (2004), "Why marketers need a new concept of culture for the global knowledge economy", International Marketing Review, Vol. 21 No. 6, pp. 563-572.

Huang, A.H., Chen, K., Yen, D.C. and Tran, T.P. (2015), “A study of factors that contribute to online review helpfulness", Computers in Human Behavior, Vol. 48, pp. 17-27.

Huang, S.S. and Crotts, J. (2019), "Relationships between Hofstede's cultural dimensions and tourist satisfaction: A cross-country cross-sample examination”, Tourism Management, Vol. 72, pp. 232241.

Huang, J.H., Huang, C.T. and Wu, S. (1996), "National character and response to unsatisfactory hotel service", International Journal of Hospitality Management, Vol. 15 No. 3, pp. 229-243.

Hwang, J. and Seo, S. (2016), "A critical review of research on customer experience management: Theoretical, methodological and cultural perspectives", International Journal of Contemporary Hospitality Management, Vol. 28 No. 10, pp. 2218-2246.

Jahandideh, B., Golmohammadi, A., Kevin, M., O‘Gorman, D. and Taheri, B. (2014), "Cross-cultural comparison of Chinese and Arab consumer complaint behavior in the hotel context", International Journal of Hospitality Management, Vol. 41, pp. 67-76.

Kim, M.G., Lee, C.H. and Mattila, A.S. (2014), "Determinants of customer complaint behavior in a restaurant context: The role of culture, price level, and customer loyalty", Journal of Hospitality Marketing and Management, Vol. 23 No. 8, pp. 885-906.

Kim, T., Kim, W.G. and Kim, H.B. (2009), "The effects of perceived justice on recovery satisfaction, trust, word-of-mouth, and revisit intention in upscale hotels", Tourism Management, Vol. 30, pp. 51-62. 
Kim, W.G. and Park, S.A. (2017), "Social media review rating versus traditional customer satisfaction: Which one has more incremental predictive power in explaining hotel performance?", International Journal of Contemporary Hospitality Management, Vol. 29 No. 2, pp. 784-802.

Kluckhohn, F. R., and Strodtbeck, F. L. (1961). Variations in value orientations. Evanston, IL: Row, Peterson.

Kroeber, A. L. and Parsons. T. (1958), "The Concepts of Culture and of Social System", American Sociological Review, Vol. 23, pp. 582-583.

Kwok, L., Xie, K. L. and Richards, T. (2017), "Thematic framework of online review research: A systematic analysis of contemporary literature on seven major hospitality and tourism journals", International Journal of Contemporary Hospitality Management, Vol. 29, pp. 307-354.

Ladhari, R., Pons, F., Bressolles, G. and Zins, M. (2011), "Culture and personal values: How they influence perceived service quality”, Journal of Business Research, Vol. 64 No. 9, pp. 951-957.

Laroche, M., Kalamas, M. and Cleveland, M. (2006), "I" versus "we" how individualists and collectivists use information sources to formulate their service expectations", International Marketing Review, Vol. 22 No. 3, pp. 279-308.

Laroche, M., Ueltschy, L. C., Shuzo, A. and Cleveland, M. (2004), "Service quality perceptions and customer satisfaction: Evaluating the role of culture", Journal of International Marketing, Vol. 12 No. 3, pp. 58-85.

Lee, S., Noh, S. and Kim, H. (2013), "A mixed methods approach to electronic word-of mouth in the openmarket context”, International Journal of Information Management, Vol. 33 No. 4, pp. 687-696.

Lee, Y. and Kramer, A. (2016), "The role of purposeful diversity and inclusion strategy (PDIS) and cultural tightness/looseness in the relationship between national culture and organizational culture", Human Resource Management Review, Vol. 26 No. 3, pp. 198-208.

Lehman, D.R., Chiu, C-Y. and Schaller, M. (2004) , "Psychology and culture", Annual Review of Psychology, Vol. 55, pp. 689-714.

Li, X., Lai, C., Harrill, R., Kline, S. and Wang, L. (2011), "When east meets west: An exploratory study on Chinese outbound tourists' travel expectations", Tourism Management, Vol. 32 No. 4, pp. 741-749.

Lincoln, Y.S. and Guba, E.G. (2000), Paradigmatic controversies, contradictions, and emerging confluences. In N.K. Denzin and Y.S. Lincoln (Eds.), Handbook of qualitative research. Thousand Oaks, CA: Sage.

Litvin, S.W., Goldsmith, R.E. and Pan, B. (2008), "Electronic word-of-mouth in hospitality and tourism management", Tourism Management, Vol. 29, pp. 458-468.

Liu, B. S-C., Furrer, O. and Sudharshan, D. (2001), "The relationships between culture and behavioral intentions toward services", Journal of Service Research, Vol. 4 No. 2, pp. 118-129. 
Liu, R. R. and McClure, P. (2001), "Recognizing cross-cultural differences in consumer complaint behavior and intentions: An empirical examination”, Journal of Consumer Marketing, Vol. 18 No. 1, pp. 54 74.

Liu, Z. and Park, S. (2015), "What Makes a Useful Online Review? Implication for Travel Product Websites", Tourism Management, Vol. 47, pp. 140-151.

Luo, C., Wu, J., Shi, Y., Yun, and Xu, Y. (2014), "The effects of individualism-collectivism cultural orientation on eWOM information”, International Journal of Information Management, Vol. 34, pp. $446-456$.

Luthans, F. and Doh, J.P. (2009), International management: Culture, strategy, and behavior, McGrawHill Irwin, New York, NY.

Lynch, J.G., Bradlow, E.T., Huber, J.C. and Lehmann, D.R. (2015), "Reflections on the replication corner: In praise of conceptual replications", International Journal of Research in Marketing, Vol. 32, Issue 4, December 2015, Pages 333-342

Ma, X., Khansa, L., Deng, Y. and Kim, S.S. (2013), "Impact of prior reviews on the subsequent review process in reputation systems", Journal of Management Information Systems, Vol. 30 No. 3, pp. 279-310.

Mariani, M.M., Baggio, R., Fuchs, M. and Höpken, W. (2018), "Business Intelligence and Big Data in Hospitality and Tourism: A Systematic Literature Review", International Journal of Contemporary Hospitality Management, Vol. 30 No. 10, pp. 3514-3554.

Mariani, M. M. and Borghi, M. (2018), "Effects of the booking.com rating system: bringing hotel class into the picture", Tourism Management, Vol. 66, pp. 47-52.

Mattila, A. S. (1999), "The role of culture and purchase motivation in service encounter evaluations", Journal of Services Marketing, Vol. 13 No. 4/5, pp. 376-389.

Mattila, A.S. (2000), "The impact of culture and gender on customer evaluations of service encounters". Journal of Hospitality and Tourism Research, Vol. 24 No. 2, pp. 263-273.

Mauri, A.G. and Minazzi, R. (2013), "Web reviews influence on expectations and purchasing intentions of hotel potential customers", International Journal of Hospitality Management, Vol. 34, pp. 99-107.

Mazanec, J.A, Crotts, J.C., Gursoy, D. and Lu, L. (2015), "Homogeneity versus heterogeneity of cultural values: An item-response theoretical approach applying Hofstede's cultural dimensions in a single nation", Tourism Management, Vol. 48, pp. 299-304.

McCollough, M. A., Berry, L.L. and Yadav, M.S. (2000), “An empirical investigation of customer satisfaction after service failure and recovery”, Journal of Service Research, Vol. 3 No. 2, pp. 121137. 
McLeod, D. (2004). Tourism, Globalization and Cultural Change: An Island Community Perspective. New York: Channel View.

McSweeney, B. (2002), “The essentials of scholarship: A reply to Geert Hofstede”. Human Relations, Vol. 55 No. 11, pp. 1363-1372.

Mellinas, J. P., María-Dolores, S.M.M. and García, J. J. B. (2015), "Booking.com: The unexpected scoring system", Tourism Management, Vol. 49, pp. 72-74.

Moran, R.T., Harris, P.R. and Moran, S. (2007), Managing Cultural Differences ( $7^{\text {th }}$ ed.), Routledge.

Nakata, C. and Sivakumar, K. (2001), "Instituting the marketing concept in a multinational setting: The role of national culture", Journal of the Academy of Marketing Science, Vol. 29 No. 3, pp. 255-275.

Nazarian, A., Atkinson, P. and Foroudi, P. (2017), "Influence of national culture and balanced organizational culture on the hotel industry's performance", International Journal of Hospitality Management, Vol. 63, pp. 22-32.

Ngai, W. T., Heung, C. S., Wong, Y. H. and Chan, K. Y. (2007), “Consumer complaint behavior of Asians and non-Asians about hotel services: An empirical analysis”, European Journal of Marketing, Vol. 41 No. 11/12, pp. 1375-1391.

Nielsen (2015), “Global trust in advertising. Winning strategies for an evolving media landscape”, available at: $\quad$ http://www.nielsen.com/us/en/insights/reports/2015/global-trust-in-advertising-2015.html (accessed October 29 2018).

Nusair, K., Parsa, H.G. and Cobanoglu, C. (2011), "Building a model of commitment for Generation Y: an empirical study on e-travel retailers", Tourism Management, Vol. 32, pp. 833-843.

O’Keefe D. J. (1998), “Justification explicitness and persuasive effect: A meta-analytic review of the effects of varying support articulation in persuasive messages". Argumentation and Advocacy, Vol. 35 No. 2, pp. 61-75.

Parker, G. and Van Alstyne, M. W. (2005) “Two-Sided Network Effects: A Theory of Information Product Design," Management Science, Vol. 51, pp. 1494-1504.

Parsons, T. (1961), Introduction, to Part IV, Culture and the Social System in Talcott Parsons et. al (eds), Theories of Society, New York: Free Press.

Parsons, T. (1971), The System of Modern Societies. Englewood Cliffs, NJ: Prentice-Hall.

Phinney, J. S. and Ong, A. D. (2007), “Conceptualization and measurement of ethnic identity: Current status and future directions", Journal of Counseling Psychology, Vol. 54 No. 3, pp. 271-281.

Pizam, A. and Sussmann, S. (1995), “Does nationality affect tourist behaviour?”, Annals of Tourism Research, Vol. 22 No. 4, pp. 901-917.

Predvoditeleva, M., Reshetnikova, K. and Slevitch, L. (2019). “Hospitality Master's program competencies: the case of Russian hotel industry", Journal of Hospitality and Tourism Education (in press). 
Racherla, P. and Friske, W. (2012), "Perceived 'usefulness' of online consumer reviews: An exploratory investigation across three services categories," Electronic Commerce Research and Applications, Vol. 11 No. 6, pp. 548-559.

Ramnath, S., Rock, S. and Shane, P. (2008), “The financial analyst forecasting literature: A taxonomy with suggestions for further research", International Journal of Forecasting, Vol. 24, 34-75.

Reimann, M., Lünemann, U.F. and Chase, R.B. (2008), "Uncertainty Avoidance as a Moderator of the Relationship between Perceived Service Quality and Customer Satisfaction", Journal of Service Research, Vol. 11 No. 1, pp. 63-73.

Reisinger, Y. and Turner, L. (1997), "Tourist satisfaction with hosts: A cultural approach comparing Thai tourists and Australian hosts", Pacific Tourism Review, Vol. 1 no. 2, pp. 147-159.

Reisinger, Y. and Crotts, J. (2010), “Applying Hofstede's national culture measures in tourism research: Illuminating issues of divergence and convergence", Journal of Travel Research, 49(2), 153-164.

Reynolds, N. and Smith, A. (2010), “Assessing the impact of response styles on cross-cultural service quality evaluation: A simplified approach to eliminating the problem", Journal of Service Research, Vol. 13 No. 2, pp. 230-243.

Rokeach, M. (1973).The nature of human values, New York: Free press.

Schein, E.H. (1985), Organizational Culture and Leadership ( $1^{\text {st }}$ ed $)$, Jossey-Bass Pub.

Schein, E.H. (1992). Organizational culture and leadership. $2^{\text {nd }}$ ed. San Francisco: Jossey-Bass.

Schwartz, S.H. (1992), "Universals in the content and structure of values: theoretical advances and empirical tests in 20 countries". In: M. Zanna (Ed.), Advances in Experimental Social Psychology, Vol. 25 New York: Academic Press, 1-66.

Sharma, P., Chen. I.S.N. and Luk, S.T.K. (2012), "Exploring the role of IND-COL as a moderator in the comprehensive service evaluation model", Journal of International Consumer Marketing, Vo. 24 No. 1-2, pp. 129-142.

Sheresheva M., Balaeva O., Predvoditeleva M., Tretyak O. and Burnatseva E. (2012), Network Strategies of Hospitality Companies in Emerging and Transitory Economies: Evidence from Russia. In N. Delener (Ed), Service Science Research, Strategy and Innovation: Dynamic Knowledge Management Methods, Hershey.

Shostack, G. (1985), Planning the service encounter. In Czepiel, A., Solomon, A.R. and Surprenant, F. (Eds), The Service Encounter, Lexington Books, New York, NY, pp. 243-54.

Sparks, B.A. and Browning, V. (2011), "The impact of online reviews on hotel booking intentions and perception of trust", Tourism Management, Vol. 32 No. 6, pp. 1310-1323.

Tajfel, H. And Turner, J. C. (1986), “The social identity theory of inter-group behaviour”, In S. Worchel and W. G. Austin (Eds.), Psychology of Intergroup Relations. Chicago: Nelson-Hall. 
Thompson, W.M., Kilani, R.K., Smith, B.B., Thomas, J., Jaffe, T.A., Delong, D.M. and Paulson, E.K. (2007), “Accuracy of Abdominal Radiography in Acute Small-Bowel Obstruction: Does Reviewer Experience Matter?” AJR. American journal of roentgenology, Vol. 188 No. 3, pp. 233-238.

Torres E. N., Fu, X. and Lehto, X. (2014), "Examining key drivers of customer delight in a hotel experience: A cross-cultural perspective”, International Journal of Hospitality Management, Vol. 36, pp. 255262.

Tse, E.C.Y. and Ho, S-C. (2009), "Service Quality in the Hotel Industry. When Cultural Contexts Matter", Cornell Hospitality Quarterly, Vol. 50 No. 4, pp. 460-474.

UNWTO (2017), “UNWTO Tourism Highlights. 2017 Edition”, available at: https://www.eunwto.org/doi/pdf/10.18111/9789284419029 (accessed March.06.2018).

Van Vaerenbergh, Y., Orsingher, C., Vermeir, I. and Larivie’, B. (2014), “A meta-analysis of relationships linking service failure attributions to customer outcomes", Journal of Service Research, Vol. 17 No. 4, pp. 381-398

Vermeulen, I.E. and Seegers, D. (2009), "Tried and tested: The impact of online hotel reviews on consumer consideration", Tourism Management, Vol. 30, p. 127.

Voss, C. A., Roth, A.V., Rosenzweig, E.D., Blackmon, K. and Chase, R.B (2004), “A tale of two countries' conservatism, service quality, and feedback on customer satisfaction", Journal of Service Research, Vol. 6 No. 3, pp. 212-230.

Wang, Y., Vela, M.R. and Tyler, K. (2008), "Cultural perspectives: Chinese perceptions of UK hotel service quality", International Journal of Culture, Tourism and Hospitality Research, Vol. 2 No. 4, pp. 312-329.

Wen, Ji, Hu, Y. and Kim, H.J. (2018), "Impact of individual cultural values on hotel guests' positive emotions and positive eWOM intention: Extending the cognitive appraisal framework", International Journal of Contemporary Hospitality Management, Vol. 30 No. 3, pp.17691787.

Xie, K. L. and So, K.K.F. (2018), "The effects of reviewer expertise on future reputation, popularity, and financial performance of hotels: insights from data- Analytics", Journal of Hospitality and Tourism Research, Vol. 42 No. 8, pp. 1187-1209.

Xie, K.L., Zhang, Z., Zhang, Z., Singh, A. and Lee, K.L. (2016), "Effects of managerial response on consumer eWOM and hotel performance: Evidence from TripAdvisor", International Journal of Contemporary Hospitality Management, Vol. 28 No. 9, pp. 2013-2034.

Yoo, B., Donthu, N. and Lenartowicz, T. (2011), "Measuring Hofstede's five dimensions of cultural values at the individual level: development and validation of CVSCALE", Journal of International Consumer Marketing, Vol. 23 No. 2, pp. 193-210. 
Yuksel, A., Kilinc, U. and Yuksel, F. (2006), “Cross-national analysis of hotel customers' attitudes toward complaining and their complaining behaviours", Tourism Management, Vol. 27 No. 1, pp. 11-24.

Zeugner-Roth, K.P., Žabkar, V. and Diamantopoulos, A. (2015) , “Consumer Ethnocentrism, National Identity, and Consumer Cosmopolitanism as Drivers of Consumer Behavior: A Social Identity Theory Perspective”, Journal of International Marketing, Vol. 23 No. 2, 2015, pp. 25-54.

Zhang, L., Wu, L. L. and Mattila, A.S. (2014), "Online reviews: The role of information load and peripheral factors", Journal of Travel Research, Vol. 55, pp. 299-310.

Zhang, Z., Zhang, Z. and Yang, Y. (2016), "The power of expert identity: How website-recognized expert reviews influence travelers' online rating behaviour", Tourism Management, Vol. 55, pp. 15-24. 